Publised in Catalysis Today, Volume 249, 1 July 2015, Pages 153-160

\title{
Impact of sulfonated hydrothermal carbon texture and surface chemistry on its catalytic performance in esterification reaction.
}

\author{
Laura Roldán $^{\mathrm{a}}$, Elisabet Pires ${ }^{\mathrm{b}}$, José M. Fraile ${ }^{\mathrm{b}}$, Enrique García-Bordejée ${ }^{\mathrm{a} *}$ \\ ${ }^{a}$ Instituto de Carboquímica (ICB-CSIC), Miguel Luesma Castán 4, E-50018 Zaragoza, \\ Spain, \\ ${ }^{\mathrm{b}}$ Instituto de Síntesis Química y Catálisis Homogénea (ISQCH), Facultad de Ciencias, \\ C.S.I.C. - Universidad de Zaragoza, E-50009 Zaragoza, Spain.
}

\begin{abstract}
A carbon material consisting of interconnected spheres of around $350 \mathrm{~nm}$ diameter has been prepared by hydrothermal synthesis at $453 \mathrm{~K}$. Subsequently, the hydrothermal carbon (HTC) has been treated in $\mathrm{N}_{2}$ at different temperatures, 573, 673, 773, $973 \mathrm{~K}$, giving rise to materials with similar spherical morphology but different microporous structure and oxygen content. Concerning porosity, the materials ranged from carbon formed exclusively by ultramicropores $(<0.7 \mathrm{~nm})$ to carbons with wider micropores. Concomitantly to the widening of micropores, the amount of oxygenated surface groups decrease as heat treatment temperature of HTC increases. Sulfonated carbon catalysts were prepared thereof and tested in the esterification of palmitic acid with methanol. The catalysts were benchmarked with a commercial activated carbon consisting of micro and mesopores that was sulfonated by the same method. The prepared materials showed significantly different catalytic activity and deactivation mechanisms, which
\end{abstract}

\footnotetext{
* Corresponding author: Tel.:+ 34 976733977; fax.: +34 976733318 E-mail address: jegarcia@icb.csic.es
} 
have been explained on the basis of their different textural properties and oxygenated surface group content.

Keywords: sulfonated hydrothermal carbon; sulfonic solids; esterification; deactivation; acid catalysts

\section{Introduction}

Esterification reactions has become a very essential reaction in the biorefinery industry for obtaining both biofuels such as biodiesel [1] and biomass derived chemicals such lubricants, surfactants etc. Biobased transportation fuels are increasingly considered as an alternative to traditional petroleum-based fuels due to the foreseen oil shortages and increasing volatility of oil-price. Additionally, the use of biodiesel is generally considered to be more environmentally benign than its petroleum-diesel counterpart due to strongly reduced sulfur and particulate emissions [2]. Current industrial biodiesel production is based on the (trans)esterification process, yielding fatty acid methyl esters (FAME) and glycerol from triglyceride feeds. This process can be catalyzed using either acid or base catalysts. Although the base-catalyzed reaction is faster, acid catalysts have a higher tolerance for free fatty acids and water present in triglyceride feeds, creating opportunities for the use of acid catalysts in biodiesel production [3]. Esterification reactions are usually catalyzed by Brønsted and Lewis liquid acid catalysts $\left(\mathrm{H}_{2} \mathrm{SO}_{4}\right.$, $\mathrm{HCl}, \mathrm{BF}_{3}, \mathrm{H}_{3} \mathrm{PO}_{4}$ ) but this poses problems of separation, corrosion and waste management. Solid acid catalyst can circumvent these problems and therefore are preferred by industry. Acidic solids are among the most used heterogeneous catalyst both for bulk [4-6] and fine chemical synthesis [6,7]. Sulfonic acids supported on inert matrixes have been proposed as interesting alternatives to classical inorganic solids 
[8,9]. Among the sulfonic functionalized acid catalysts, sulfonated carbons have shown outstanding performance $[10,11]$. Moreover, carbon materials have some intrinsic advantages over other solid acid catalyst. Carbon materials have a tunable porosity and surface chemistry [12-14]. By changing the carbonization temperature, it is possible to prepare carbon materials with different degrees of graphitization and thus hydrophilic/hydrophobic character. Carbon materials have an inherently renewable origin and sometimes they are prepared using very mild conditions such as hydrothermal carbon [15]. In addition, sulfonated carbons are more stable and watertolerant in hydrothermal conditions required for biomass conversion than other solid acid catalyst [16].

Hara et al. [10] prepared a strong and stable solid acid carbon catalyst by incomplete carbonization of sulfoaromatic hydrocarbons derived from naphthalene, which consisted of small polycyclic aromatic carbon sheets with attached $\mathrm{SO}_{3} \mathrm{H}$ groups. Using glucose as starting material, sulfonated carbon catalysts were prepared either by thermal carbonization at low temperature (673 K) [17] or by hydrothermal carbonization [18]. These carbonaceous materials showed higher turnover rates than other solid acid catalysts. However, a detailed study about the textural properties of these materials and the reasons of their superb activity is lacking.

Microporosity was created in sulfonated carbons prepared using cellulose as precursor and carbonized at several temperatures from 523 to $873 \mathrm{~K}$ [19]. The solid prepared at a carbonization temperature of $773 \mathrm{~K}$ showed the best turnover rate in esterification due to a compromise between high surface area and high density of sulfonic sites. Unfortunately, no result about reusability of these catalysts was shown. Mesoporous sulfonated carbons have been prepared using mesoporous silicas as sacrificial template [20-22]. The ordered mesoporous carbons with sulfonic groups exhibited larger initial 
reaction rates than other solid acid catalyst, which was attributed to the larger pore size and hydrophobic surface that can accommodate long chain fatty acids and reject water. Moreover, these catalysts showed excellent reusability in acid catalyzed reactions, which is attributed to their mesoporosity and good attachment of sulfonic groups to carbon. Sulfonated carbon nanotubes have also been used for esterification reactions showing deactivation, which is attributed to the adsorption of products [6]. On the contrary, carbon nanofibers functionalized with aryl sulfonic groups by diazonium chemistry were more stable and more active than other solid acids in esterification reaction. This was attributed to absence of microporosity, which facilitates the accessibility of reactants to sulfonic groups on CNF surface [23].

In a previous work [24], we tested sulfonated hydrothermal carbons in the esterification of palmitic acid with methanol. It was observed that the catalyst suffered some deactivation upon reuse which was demonstrated to be due to the formation of surface methyl sulfonyl esters. The textural properties of sulfonated hydrothermal carbons were characterized extensively in previous work [25]. The material showed ultramicropores, which became accessible to reactants under polar solvents due to breaking the hydrogen bonds between the high loading of acidic groups (sulfonic and carboxylic) present in the pore surface.

In all the above mentioned works, carbon materials of very different surface chemistry and texture have been used. Due to the scattering of the properties of these materials, withdrawing characterization-performance relationships is not a straightforward task. There is some consensus that a high density of acid sites is beneficial for activity. This could be one of the reasons why poorly graphitized materials with more defects, i.e. pyrolized at low temperatures, outperform highly graphitized materials [19]. It is not yet clear enough why some carbons exhibit deactivation upon reuse while others do not. 
The need to shed some light into these aspects prompted us to prepare HTC materials heat-treated at different temperatures. This enabled the preparation of sulfonated HTC catalysts with a gradual variation of the porosity and surface chemistry. To the best of our knowledge, the effect of annealing temperature of HTC on its catalytic performance has not been studied systematically. The sulfonated HTC catalysts have been benchmarked against a sulfonated activated carbon with high surface area and high carbonization degree. The different textural properties and surface chemical composition of the materials can account for the different catalytic activity and deactivation behavior.

\section{Experimental}

\subsection{Preparation of sulfonated hydrothermal carbons}

D-glucose was purchased from Sigma-Aldrich. Norit SX Ultra Cat 8020-1 was a gift from CABOT. Hydrothermal carbon (HTC) synthesis was carried out from D-glucose (25 $\mathrm{mL}, 1 \mathrm{M}$ in water) as described previously [24,26]. Subsequently, as-synthetized HTC carbon was heat treated under $\mathrm{N}_{2}$ flow at different temperatures from 573 to $973 \mathrm{~K}$ using a ramp of $5 \mathrm{~K} / \mathrm{min}$ and a holding time of $2 \mathrm{~h}$. The HTC carbon materials were named as HTC- followed by calcination temperature in K.

To prepare the sulfonated acid catalysts, the resulting material was then treated with concentrated (>96\%) sulfuric acid $\left(20 \mathrm{~mL} \mathrm{H}_{2} \mathrm{SO}_{4} / \mathrm{g}\right.$ solid) under argon atmosphere at $423 \mathrm{~K}$ during $15 \mathrm{~h}$. The sulfonated samples were then washed thoroughly with hot distilled water until neutrality of the filtrate and dried overnight at $378 \mathrm{~K}$. The sulfonated catalyst are denoted by adding $-\mathrm{SO}_{3} \mathrm{H}$ to the name of the carbon precursor.

\subsection{Characterization}


Surface areas were determined by $\mathrm{N}_{2}$ adsorption at $77 \mathrm{~K}$ (BET) using a Micromeritics ASAP 2020 apparatus, after outgassing for $4 \mathrm{~h}$ at $423 \mathrm{~K}$. Alternatively, it was also determined by $\mathrm{CO}_{2}$ adsorption (Dubinin-Radushkevich) at $273 \mathrm{~K}$ up to 1 bar in the same apparatus, after outgassing under the same conditions.

C,H,S elemental analysis was carried out by combustion in a ThermoFlash 1112 elemental analyser equipped with a TCD detector. Oxygen analysis was done by direct assay which involves pyrolysis of the sample at $1070{ }^{\circ} \mathrm{C}$ in a nickel/carbon bed under a known He flow. The outlet flow, after passing a separation column, ends in a TCD detector. The oxygen content of sample is quantified on the basis of CO analysed.

SEM analysis was carried out with a SEM EDX Hitachi S-3400 N microscope with variable pressure up to $270 \mathrm{~Pa}$ and with an EDX Röntec XFlash de $\mathrm{Si}(\mathrm{Li})$ analyzer. The samples were sputtered with gold previously to measurements. The images were obtained from the secondary electron signal.

Scanning transmission electron microscopy (STEM) of sulfonated hydrothermal carbon was carried out using a FEI TECNAI F30 electron microscope equipped with Gatan Energy Filter and cold field emission gun (FEG) operated at $300 \mathrm{kV}$ with 1.5 A lattice resolution. TEM specimens were prepared by ultrasonic dispersion in ethanol and a drop of the suspension was applied to a holey carbon support grid. The elemental S, C and $\mathrm{O}$ profiles along hydrothermal carbon sphere were collected using Energy Dispersive X-Ray Analysis (EDX).

The total amount of acid sites on each catalyst was determined by back titration. The solid (50 mg) was added to $25 \mathrm{~mL}$ of $0.01 \mathrm{M} \mathrm{NaOH}$ solution and allowed to equilibrate under stirring for $1 \mathrm{~h}$. Thereafter, it was titrated with $0.05 \mathrm{M}$ potassium hydrogen phthalate solution using a Crison $\mathrm{pH}$ Burette 24 . 


\subsection{Esterification of palmitic acid with methanol}

Palmitic acid (1.92 g, $7.5 \mathrm{mmol})$, methanol $(3.04 \mathrm{ml}, 75.0 \mathrm{mmol})$, sulfonated carbon $\left(0.059 \mathrm{mmol} \mathrm{SO} \mathrm{S}_{3} \mathrm{H}\right)$, and 1-methylnaphthalene $(0.30 \mathrm{~g}, 2.1 \mathrm{mmol})$ as internal standard were stirred $(\approx 1000 \mathrm{rpm})$ in a round flask immersed into a silicone bath at $85^{\circ} \mathrm{C}$ under reflux conditions. Reaction was monitored by gas chromatography (HP-5890-II).

\section{Results and discussion}

\subsection{Characterisation}

HTC materials were prepared from diluted glucose solutions which gave rise to spheres of $350 \mathrm{~nm}$ average diameter (Figure 1a). These spheres are not isolated but condensed to form aggregates. Upon calcination between 573-973 K the spherical morphology is retained but the diameter of the spherical basic units increases slightly. The average sphere diameters are 400, 450 and $520 \mathrm{~nm}$ for samples heat-treated at 673,773 and 973 K, respectively (Figure 1). 

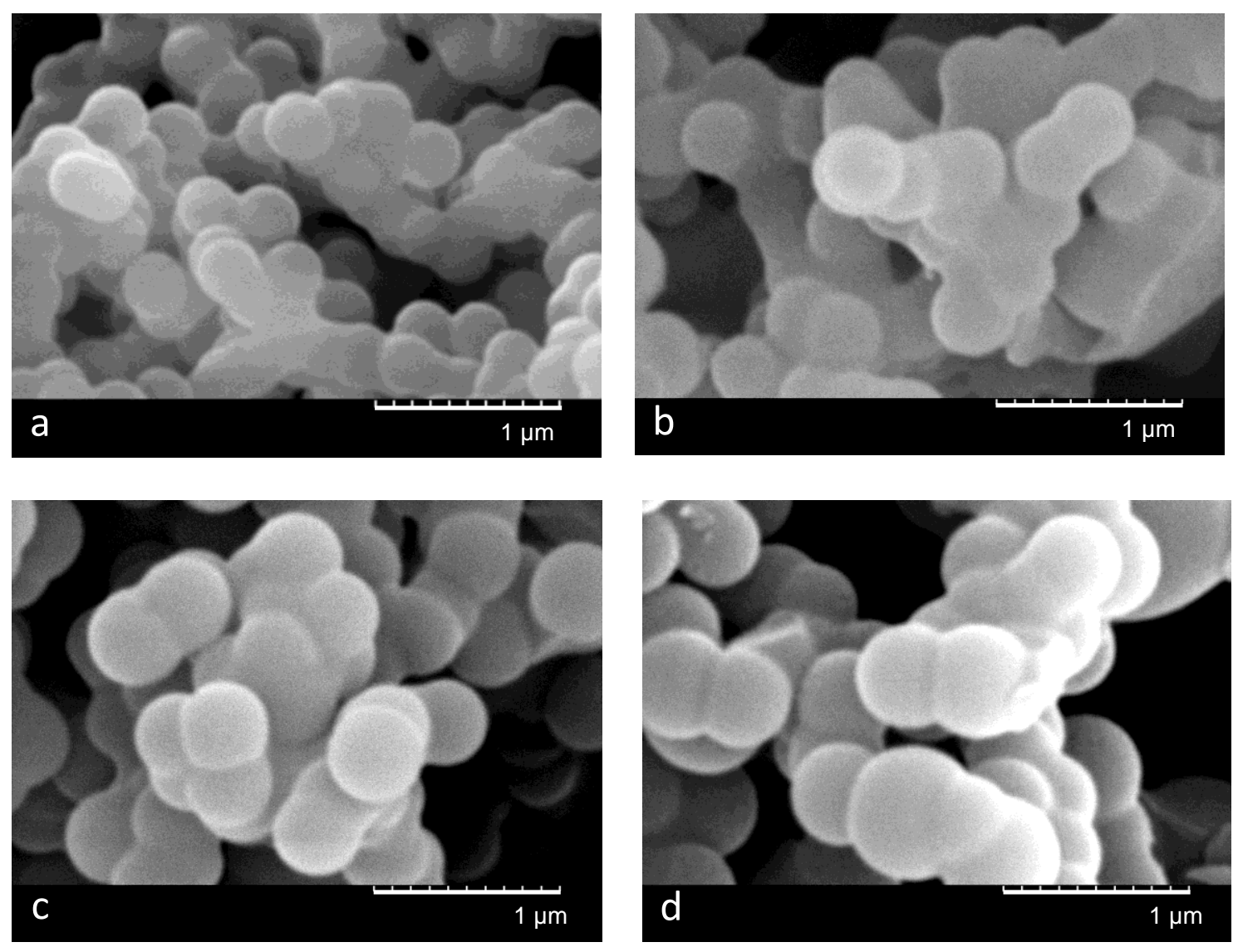

Figure 1. SEM images of as synthetized HTC (a) and HTC calcined at different temperatures: HTC-673 (b), HTC-773 (c) and HTC-973 (d).

Table 1 displays the results of elemental analysis of HTC carbons pyrolized at different temperatures and of commercial activated carbon both before and after sulfonation. Their textural properties are shown in table 2. As pyrolysis temperature increases up to $973 \mathrm{~K}$, a decrease of oxygen content takes place from 27 to $2.5 \mathrm{wt} \%$. After sulfonation, the $\mathrm{O}$ content increases due to the oxidation of carbon surface. Despite the oxidation of carbon surface after sulfonation, the same trend in oxygen content is maintained for sulfonated carbons, that is, the higher the heat-treatment temperature of carbons, the lower the oxygen content. 
Table 1. Weight composition measured by elemental analysis of HTC heat-treated at different temperatures and sulfonated and commercial activated carbon

$$
\text { Composition (wt\%) }
$$

\begin{tabular}{lllll} 
Carbon sample & $\mathrm{C}$ & $\mathrm{H}$ & $\mathrm{O}$ & $\mathrm{S}$ \\
\hline $\mathrm{HTC}$ & 66.3 & 4.4 & 26.9 & 0 \\
HTC-SO $\mathrm{H}$ & 58.9 & 2.1 & 37.6 & 1.9 \\
$\mathrm{HTC}-573$ & 70.0 & 4.2 & 24.3 & 0 \\
HTC-573- $\mathrm{SO}_{3} \mathrm{H}$ & 57.9 & 2.4 & 38.6 & 1.8 \\
HTC-673 & 78.8 & 3.5 & 15.9 & 0 \\
HTC-673- $\mathrm{SO}_{3} \mathrm{H}$ & 56.9 & 2.9 & 34.4 & 2.4 \\
HTC-773 & 84.8 & 2.9 & 10.0 & 0 \\
HTC-773- $\mathrm{SO}_{3} \mathrm{H}$ & 66.7 & 2.4 & 26.3 & 2.4 \\
HTC-973 & 94.0 & 1.1 & 2.5 & 0 \\
HTC-973- $\mathrm{SO}_{3} \mathrm{H}$ & 72.6 & 1.4 & 11.1 & 4.3 \\
SX Norit & 83.0 & 1.1 & 13.0 & 0.08 \\
SX Norit-SO & 84.6 & 0.4 & 13.9 & 0.64 \\
\hline
\end{tabular}

The $\mathrm{N}_{2}$ adsorption isotherms of HTC carbons heat-treated at temperatures equal or lower than $673 \mathrm{~K}$ show negligible adsorption both before and after sulfonation (Figure 2 A), resulting in very low BET surface areas $4-7 \mathrm{~m}^{2} / \mathrm{g}$ (Table 2). Nevertheless, $\mathrm{CO}_{2}$ adsorption at $273 \mathrm{~K}$ is apparent in these samples (Figure 3A). The surface area determined by this later method is in the range $200-300 \mathrm{~m}^{2} / \mathrm{g}$ (Table 2). This discrepancy between Surface areas determined by $\mathrm{N}_{2}$ and $\mathrm{CO}_{2}$ has been previously reported [27,28], and it is attributed to the presence of narrow micropores $(<0.7 \mathrm{~nm})$, also called "ultramicropores", in which the diffusion of $\mathrm{N}_{2}$ at $77 \mathrm{~K}$ is kinetically 
hindered. STEM EDX analysis of sulfonated carbons revealed that the sulfonic groups are evenly distributed throughout all carbon microspheres of $\mathrm{HTC}-\mathrm{SO}_{3} \mathrm{H}$, indicating that sulfonic groups are present not only on the external surface of the spheres but also inside the "ultramicropores" [25].

Table 2. Textural properties of HTC heat-treated at different temperatures, of commercial activated carbon and of these after sulfonation.

\begin{tabular}{|c|c|c|c|c|c|c|}
\hline \multirow{5}{*}{ Cabon sample } & \multicolumn{2}{|c|}{$\mathrm{N}_{2}$ adsorption } & \multicolumn{2}{|c|}{$\mathrm{CO}_{2}$ adsorption } & \multirow{2}{*}{$\begin{array}{c}\text { Micropore } \\
\text { volume } \\
-\mathrm{V}_{\text {mic }}{ }^{\mathrm{a}}\end{array}$} & \multirow{2}{*}{$\begin{array}{l}\text { Mesopore } \\
\text { volume } \\
\mathrm{V}_{\text {mes }}{ }^{\mathrm{b}}\end{array}$} \\
\hline & Surface & Pore & Surface & Pore volume & & \\
\hline & area & volume & area & $\left(\mathrm{V}_{\mathrm{u}}\right)$ & & \\
\hline & $\left(\mathrm{S}_{\mathrm{N} 2}\right)$ & $\left(\mathrm{V}_{\mathrm{p}}\right)$ & $\left(\mathrm{S}_{\mathrm{CO} 2}\right)$ & & & \\
\hline & $\left(\mathrm{m}^{2} \mathrm{~g}^{-1}\right)$ & $\left(\mathrm{cm}^{3} \mathrm{~g}^{-1}\right)$ & $\left(\mathrm{m}^{2} \mathrm{~g}^{-1}\right)$ & $\left(\mathrm{cm}^{3} \mathrm{~g}^{-1}\right)$ & $\left(\mathrm{cm}^{3} \mathrm{~g}^{-1}\right)$ & $\left(\mathrm{cm}^{3} \mathrm{~g}^{-1}\right)$ \\
\hline HTC & 7.0 & 0.014 & 142 & 0.06 & 0.0020 & 0.012 \\
\hline $\mathrm{HTC}-\mathrm{SO}_{3} \mathrm{H}$ & 4.1 & 0.009 & 224 & 0.09 & 0.0017 & 0.007 \\
\hline HTC-573 & 5.1 & 0.006 & 225 & 0.09 & 0.0016 & 0.005 \\
\hline
\end{tabular}




\begin{tabular}{lcccccc}
\hline $\mathrm{HTC}-573-\mathrm{SO}_{3} \mathrm{H}$ & 4.6 & 0.010 & 254 & 0.10 & 0.0017 & 0.008 \\
$\mathrm{HTC}-673$ & 5.0 & 0.006 & 296 & 0.12 & 0.0016 & 0.005 \\
$\mathrm{HTC}-673-\mathrm{SO}_{3} \mathrm{H}$ & 4.2 & 0.008 & 300 & 0.12 & 0.0020 & 0.006 \\
$\mathrm{HTC}-773$ & 382 & 0.170 & 451 & 0.15 & 0.1400 & 0.033 \\
$\mathrm{HTC}-773-\mathrm{SO}_{3} \mathrm{H}$ & 341 & 0.150 & 317 & 0.13 & 0.1100 & 0.042 \\
$\mathrm{HTC}-973$ & 370 & 0.220 & 608 & 0.24 & 0.2100 & 0.008 \\
$\mathrm{HTC}-973-\mathrm{SO}_{3} \mathrm{H}$ & 109 & 0.070 & 285 & 0.11 & 0.0550 & 0.015 \\
$\mathrm{SX}$ Norit & 949 & 0.770 & 581 & 0.23 & 0.3100 & 0.450 \\
SX Norit- $\mathrm{SO}_{3} \mathrm{H}$ & 925 & 0.750 & 585 & 0.23 & 0.3000 & 0.440 \\
& & & & & & \\
\hline
\end{tabular}

\footnotetext{
a calculated by non local density functional theory (NLDFT) model applied to $\mathrm{N}_{2}$ adsorption

${ }^{\mathrm{b}}$ calculated by substracting micropore volume $\left(\mathrm{V}_{\text {mic }}\right)$ from total pore volume $\left(\mathrm{V}_{\mathrm{p}}\right)$.
}

$\mathrm{N}_{2}$ adsorption exhibits a breakthrough for HTC heat treated at $773 \mathrm{~K}$ (Figure 2A). The isotherms for HTC pyrolized at $773 \mathrm{~K}$ and higher temperatures corresponds to type II isotherm indicative of microporous material [29]. For these materials, the surface areas measured by $\mathrm{N}_{2}$ are not negligible and in the same range as those measured by $\mathrm{CO}_{2}$ adsorption suggesting the presence of "supermicropores" $(>0.7 \mathrm{~nm})$. Therefore, when treatment temperature is equal or above $773 \mathrm{~K}$, the ultramicropores, which were present in as-synthetized HTC, became wider. The widening of pore diameter may be ascribed to the removal of oxygenated surface groups and also to the swelling of the pores as denoted by the enlargement of the microsphere size observed in Figure 1. Figure 2B displays the adsorption isotherm of SX Norit before and after sulfonation. The isotherm of commercial carbon is of the IV-type [29] with hysteresis at high relative pressures which indicates that this material contains both micro and mesoporosity. 
Figure 3 shows the $\mathrm{CO}_{2}$ adsorption isotherms of original and sulfonated $\mathrm{HTC}$ carbons. $\mathrm{CO}_{2}$ adsorption increases as calcination temperature increases. After sulfonation the $\mathrm{CO}_{2}$ adsorption exhibits distinct behaviour depending on the calcination temperature. Until $673 \mathrm{~K}$ (Figure 3A), the sulfonated catalyst adsorbed higher amount of $\mathrm{CO}_{2}$ than pristine HTC carbon while the reverse holds for HTC calcined at temperatures of $673 \mathrm{~K}$ and above and for Norit SX (Figure 3B).

The variation of surface area and pore volume after sulfonation is very marginal for most of the samples $(<10 \%)$ except for that pyrolised at $973 \mathrm{~K}(70 \%$ decrease $)$. The morphology and size of the spherical particles observed by SEM does not change upon sulfonation in none of the samples. Therefore, the pronounced decrease of surface area in HTC-973- $\mathrm{SO}_{3} \mathrm{H}$ can not be attributed to external changes but to the collapse of the pores.

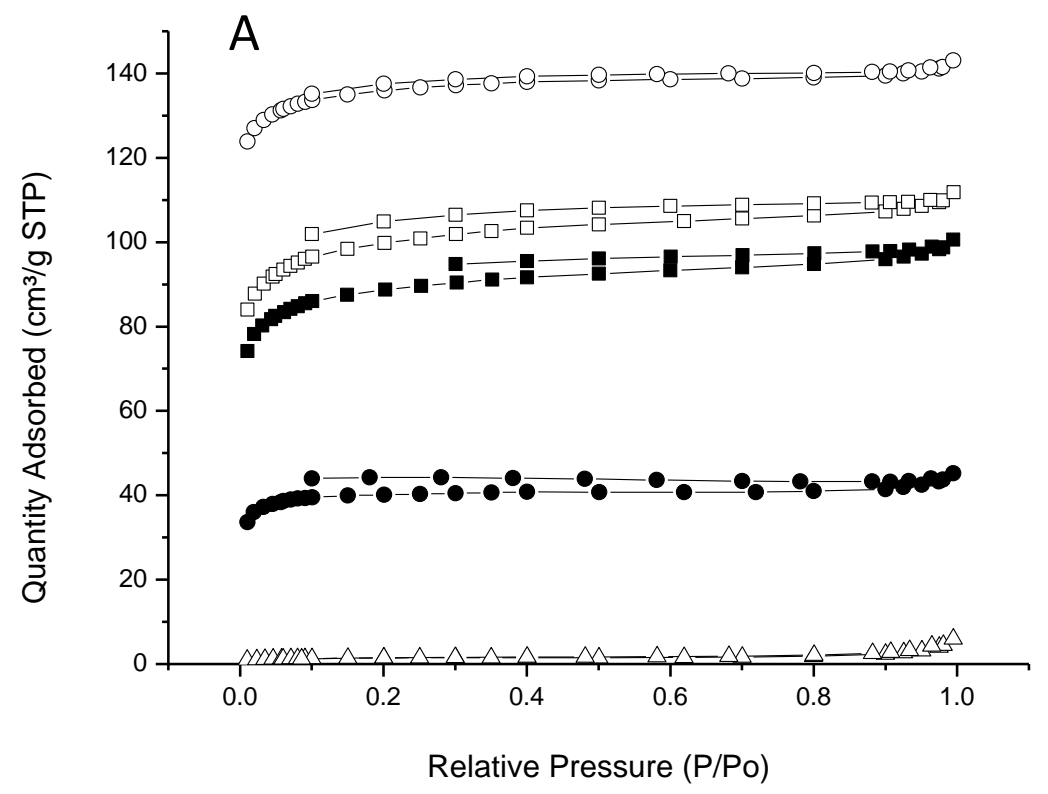




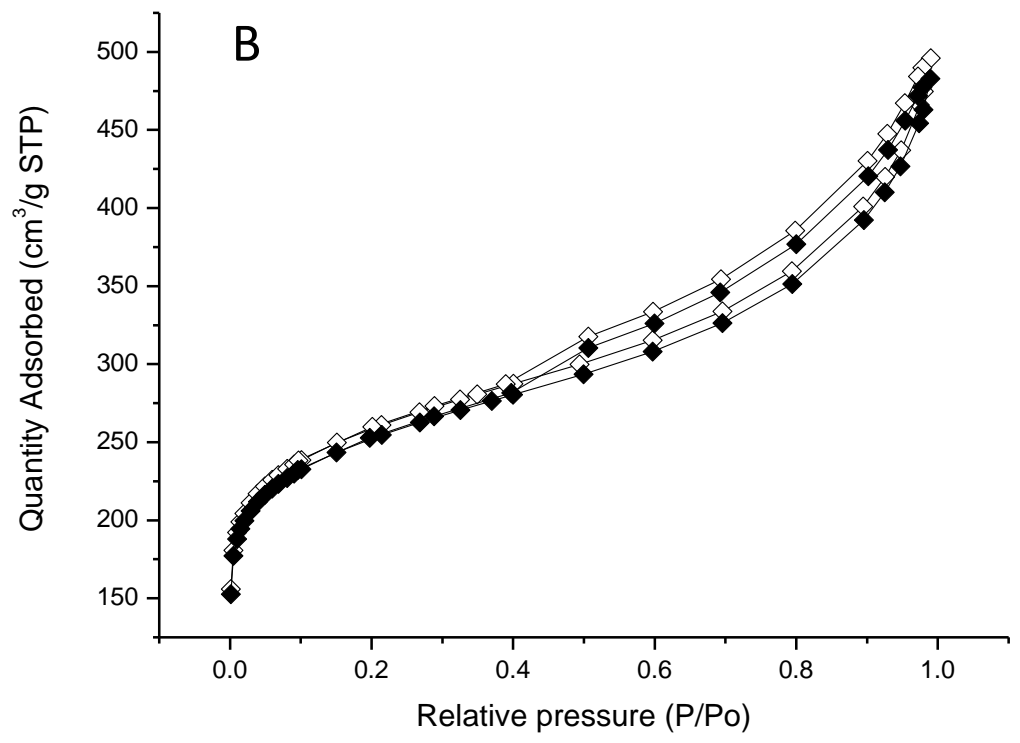

Figure 2. $\mathrm{N}_{2}$ adsorption isotherms of HTC carbons heat-treated at different temperatures and after sulfonation (A), and those of commercial activated carbon as received and after sulfonation $(B)$ : $(\triangle)$ HTC (this isotherm is similar to that of HTC-573, HTC-673, HTC- $\mathrm{SO}_{3} \mathrm{H}, \mathrm{HTC}-573-\mathrm{SO}_{3} \mathrm{H}, \mathrm{HTC}-673-\mathrm{SO}_{3} \mathrm{H}$, i.e. insignificant adsorption); ( $\square$ ) HTC-

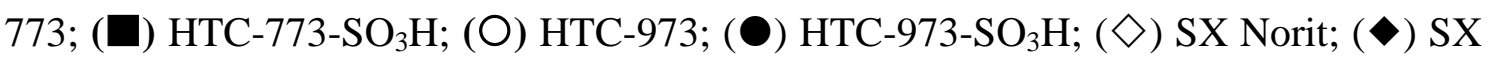
Norit- $\mathrm{SO}_{3} \mathrm{H}$. 

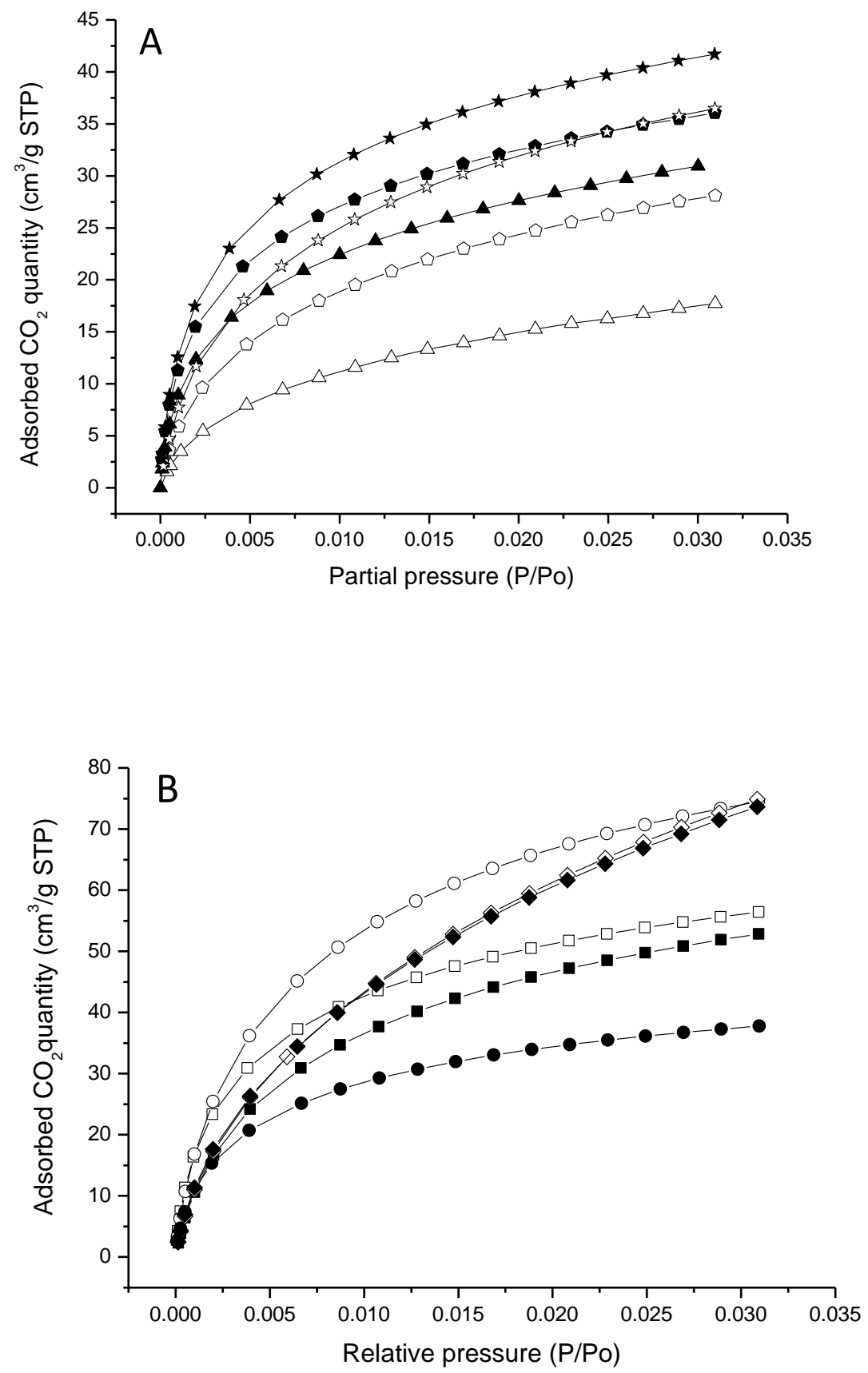

Figure 3. $\mathrm{CO}_{2}$ adsorption isotherms of $\mathrm{HTC}$ carbons heat-treated at different temperatures and after sulfonation and those of commercial activated carbon as received and after sulfonation. A: $(\triangle)$ HTC, $(\Delta)$ HTC- $\mathrm{SO}_{3} \mathrm{H},(\triangle)$ HTC-573, $(\mathbf{\bullet})$, HTC-573-

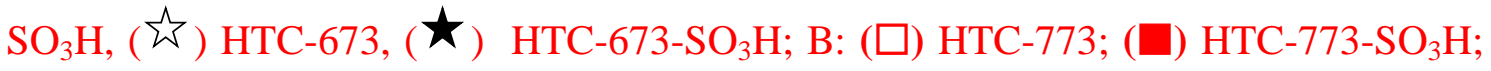
(○) HTC-973; (๑) HTC-973-SO ${ }_{3} \mathrm{H} ;(\diamond)$ SX Norit; ( ) SX Norit-SO ${ }_{3} \mathrm{H}$.

\subsection{Catalytic performance}


The catalysts were tested in the esterification of palmitic acid with methanol. Figure 4 shows the methyl palmitate yield as a function of time in two consecutive runs for the different sulfonated carbons. For a clearer comparison of the different catalysts, ester yields after 4 hours in first and second use of the catalysts are depicted in left y-axis of Figure 5. The percentage of conversion decay in second use is shown in right y-axis. The $\mathrm{x}$-axis displays the sulfonated HTC catalysts ordered in sequence of increasing heat treatment temperature and sulfonated SX Norit has been added at the end. It is a clear turning point both in catalytic activity and in the percentage of deactivation in the second use as heat treatment temperature increases. The turning point occurs for sample heat-treated at $773 \mathrm{~K}$. In the first use, the sulfonated catalyst prepared from HTC heat treated at $673 \mathrm{~K}$ is the most active, although only slightly more than those heat-treated at lower temperatures. However, the sulfonated catalyst prepared from HTC treated at $773 \mathrm{~K}$ shows significantly less activity than that prepared from HTC heat-treated at 673 K. For further increase of heat-treatment temperature to $973 \mathrm{~K}$, the catalytic behaviour follows the same trend, i.e. decreasing conversion down to negligible values. Sulfonated SX Norit exhibited also a low activity although slightly larger than that of HTC-973$\mathrm{SO}_{3} \mathrm{H}$. On the other hand, the percentage of deactivation in the second use is more severe for the catalysts that showed less activity in the first use. The activity of HTC773- $\mathrm{SO}_{3} \mathrm{H}, \mathrm{HTC}-973-\mathrm{SO}_{3} \mathrm{H}, \mathrm{SX}$ Norit- $\mathrm{SO}_{3} \mathrm{H}$ decays around $60-80 \%$ whereas the activity of sulfonated catalyst prepared from HTC pyrolised at temperatures of $673 \mathrm{~K}$ or below diminished only between 14-22\% (Figure 5). 


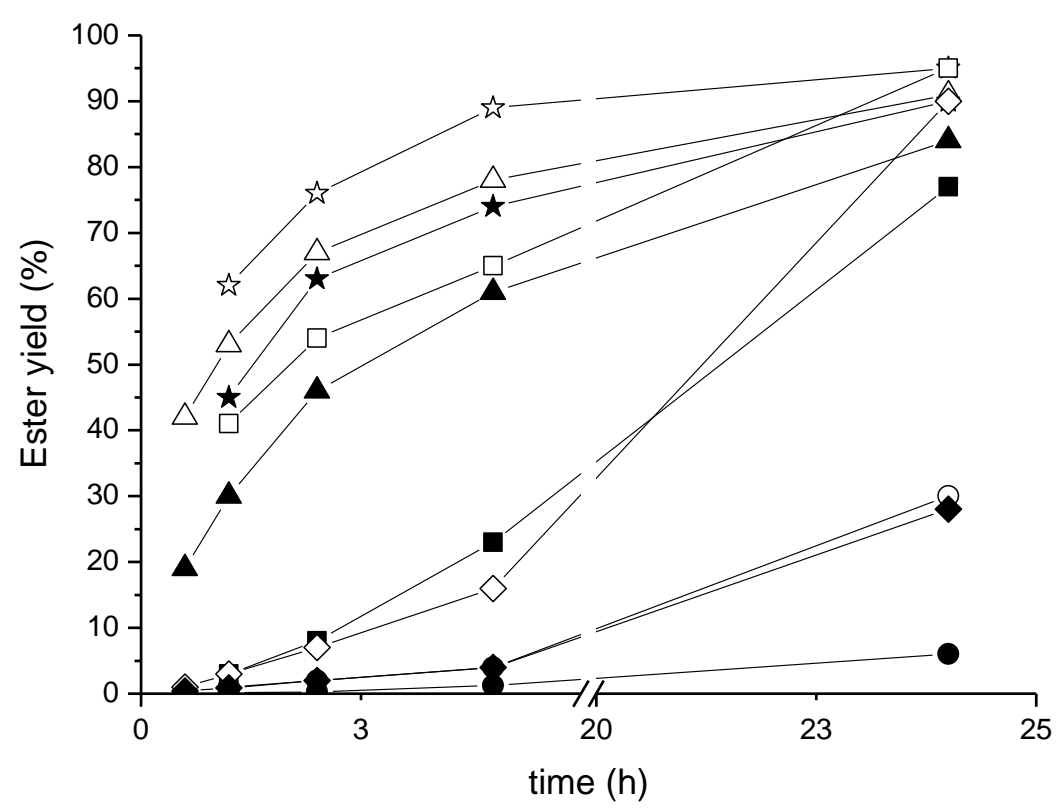

Figure 4. Methyl palmitate yield as a function of time for sulfonated carbons: $(\triangle, \mathbf{A})$

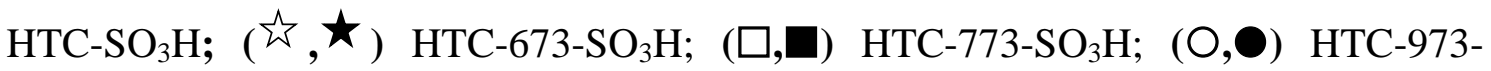
$\mathrm{SO}_{3} \mathrm{H} ;(\diamond, \diamond) \mathrm{SX}$ Norit. Empty symbols correspond to the first run and filled symbols to the reuse.

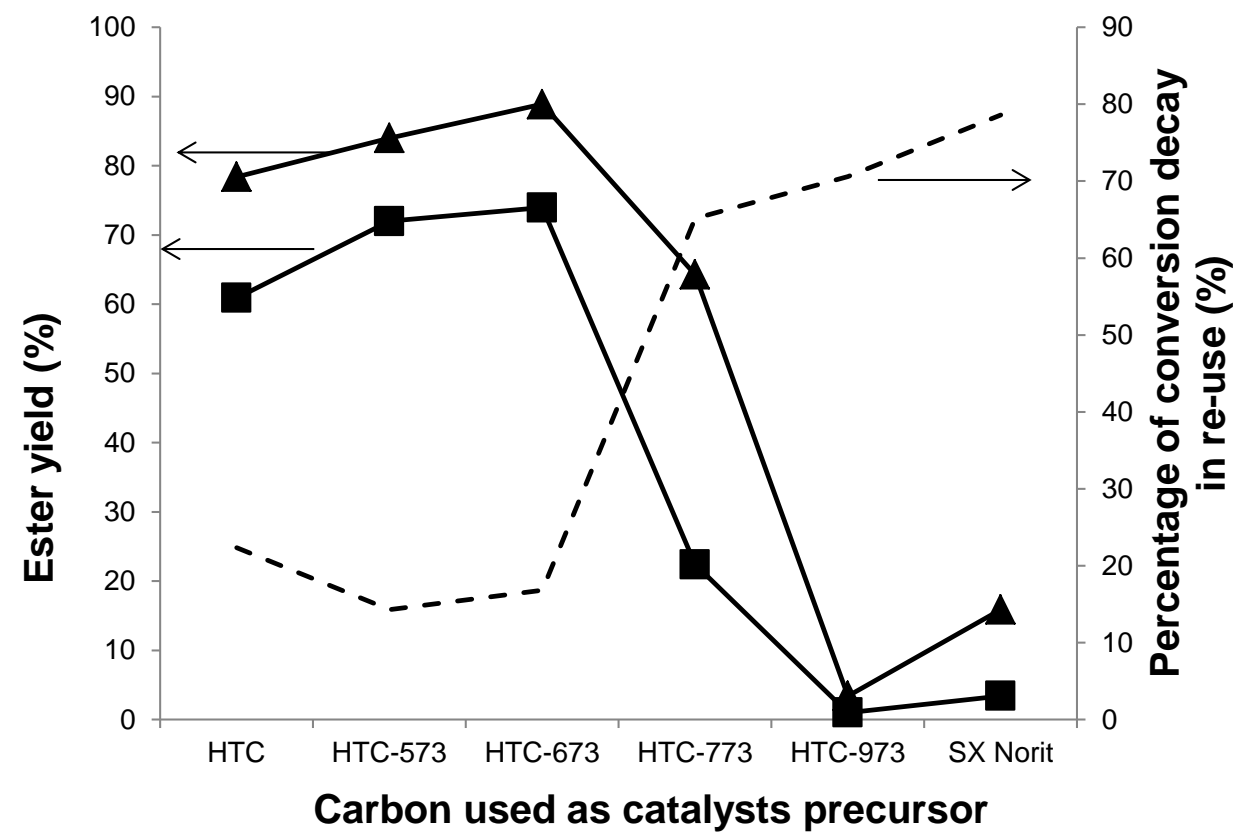


Figure 5. Methyl palmitate ester yield at first ( $\boldsymbol{\Delta}$, left y-axis) and second use ( $\boldsymbol{\square}$, left yaxis) after 4 hours reaction time and the corresponding percentage of conversion decay in re-use (dashed line, right y-axis) of the different sulfonated catalysts.

Table 3. Textural and acidity characterisation of catalysts before and after reaction.

\begin{tabular}{|c|c|c|c|c|c|c|}
\hline Catalyst & $\begin{array}{c}\text { Surface } \\
\text { area } \\
\text { by } \mathrm{N}_{2} \\
\text { adsorption } \\
\left(\mathrm{m}^{2} / \mathbf{g}\right)\end{array}$ & $\begin{array}{c}\text { Surface } \\
\text { area } \\
\text { by } \mathrm{CO}_{2} \\
\text { adsorption } \\
\left(\mathrm{m}^{2} / \mathrm{g}\right)\end{array}$ & $\begin{array}{c}\text { Total } \\
\text { acidity } \\
(\mathrm{mmol} / \mathrm{g})\end{array}$ & $\begin{array}{c}\text { Sulfonic } \\
\text { acidity }^{(a)}\end{array}$ & $\begin{array}{c}\text { Non- } \\
\text { sulfonic } \\
\text { acidity } \\
\text { (mmol/g) }\end{array}$ & $\begin{array}{c}\text { Surface- } \\
\text { normalized } \\
\text { sulfonic } \\
\text { acidity }^{(b)} \\
\left(\mathbf{m m o l} / \mathbf{m}^{2}\right)\end{array}$ \\
\hline $\mathrm{HTC}-\mathrm{SO}_{3} \mathrm{H}$ & 4.1 & 244 & 5.43 & 0.59 & 4.84 & 0.0024 \\
\hline HTC-SO ${ }_{3} \mathrm{H}$ used & 4.8 & 246 & 4.14 & 0.57 & 3.57 & 0.0023 \\
\hline HTC-573- $\mathrm{SO}_{3} \mathrm{H}$ & 4.6 & 254 & 5.46 & 0.56 & 4.90 & 0.0022 \\
\hline HTC-573-SO ${ }_{3} \mathrm{H}$ used & 4.5 & 243 & 3.18 & 0.55 & 2.63 & 0.0022 \\
\hline HTC-673- $\mathrm{SO}_{3} \mathrm{H}$ & 4.2 & 300 & 3.76 & 0.74 & 3.02 & 0.0024 \\
\hline HTC-673- $\mathrm{SO}_{3} \mathrm{H}$ used & 4.0 & 233 & 3.24 & 0.55 & 2.69 & 0.0023 \\
\hline $\mathrm{HTC}-773-\mathrm{SO}_{3} \mathrm{H}$ & 341 & 317 & 2.29 & 0.74 & 1.55 & 0.0023 \\
\hline HTC-773-SO ${ }_{3} \mathrm{H}$ used & 24 & 466 & 1.13 & 0.63 & 0.50 & 0.0013 \\
\hline HTC-973- $\mathrm{SO}_{3} \mathrm{H}$ & 109 & 285 & 2.24 & 1.35 & 0.89 & 0.0047 \\
\hline HTC-973-SO ${ }_{3} \mathrm{H}$ used & 3.8 & 487 & 0.92 & 0.69 & 0.23 & 0.0014 \\
\hline $\mathrm{SX}$ Norit-SO ${ }_{3} \mathrm{H}$ & 925 & 581 & 0.65 & 0.20 & 0.45 & 0.0003 \\
\hline $\mathrm{SX}$ Norit- $\mathrm{SO}_{3} \mathrm{H}$ used & 660 & 376 & 0.55 & 0.16 & 0.39 & 0.0004 \\
\hline
\end{tabular}

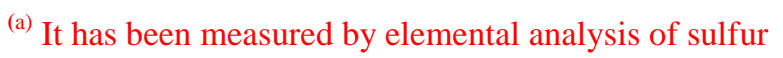

(b) Calculated using the surface area measured by $\mathrm{CO}_{2}$ chemisorption
}

Table 3 shows some characterization parameters of the catalyst before and after reaction. The sulfonic acidity was estimated by the sulfur content determined by 
elemental analysis since XPS revealed that all the sulfur was present as sulfonic groups [26]. Total acidity was determined by back titration and non-sulfonic acidity by difference between total acidity and sulfonic acidity. The differences in activity cannot be correlated to the initial surface loading of sulfonic groups (last column of Table 3). The catalyst prepared from HTC-673 has similar sulfonic acid surface loading than that prepared from HTC-773 but they have substantially different activity. Sulfonated carbons prepared from HTC-973 and SX Norit have the highest and the lowest sulfonic acid surface loading, respectively, but they both lead to the lowest reaction rates. In order to find some correlation of the trends observed in Figure 5 with some characterisation parameters, Figure 6 plots the variation of the non-sulfonic acidity (carboxylic acids+phenol) of sulfonated carbons (left y-axis) and the BET surface of carbon materials measured by $\mathrm{N}_{2}$ physisorption (right $\mathrm{y}$-axis) for the same carbons materials as in Figure 5. The two parameters depicted in Figure 6 undergo a sudden change at the same catalyst that exhibited the turning point in Figure 5, i.e. for catalyst prepared from HTC pyrolized at $773 \mathrm{~K}$. At this treatment temperature, a sudden increase of surface area measured by $\mathrm{N}_{2}$ adsorption takes place due to the widening of ultramicropores. In addition, the amount of non-sulfonic acid groups in sulfonated carbon drops pronouncedly at $773 \mathrm{~K}$ heat treatment temperature (Figure 6). The commercial activated carbon (SX Norit), which has the highest surface area and the lowest amount of oxygenated acid groups, corroborates the trends, suggesting that these two parameters could be the reason of the catalytic and deactivation behaviour. According to this, it seems that a high surface area of wider micropores and a poor amount of oxygenated acid sites, i.e. more graphitic planes exposed, are detrimental factors for both the catalytic and reusability performance. 
Some leaching of sulfonic groups (decrease of sulfonic acidity Table 3) can explain part of deactivation of catalysts with high surface area and low density of oxygenated acid groups, i.e. those prepared from HTC calcined at temperatures above $773 \mathrm{~K}$ and SX Norit- $\mathrm{SO}_{3} \mathrm{H}$. However, the later only loses $20 \%$ of sulfonic groups and its activity decays $78 \%$ in second use. In these cases, the formation of methyl sulfonyl esters does not seem to be the major cause of deactivation since these species were not detected by NMR (not shown here). The textural characterisation of used catalysts (Table 3), which were thoroughly rinsed with methanol and dichloromethane prior to the measurement, revealed some interesting evidences about the mechanism of deactivation. The surface areas measured by $\mathrm{N}_{2}$ decrease significantly after reaction in samples calcined at temperatures above $773 \mathrm{~K}$ and $\mathrm{SX}$ Norit- $\mathrm{SO}_{3} \mathrm{H}$, while those measured by $\mathrm{CO}_{2}$ increase in samples calcined at temperatures above $773 \mathrm{~K}$ and decreases in $\mathrm{SX}$ Norit-SO ${ }_{3} \mathrm{H}$. This suggests that wider micropores either become narrower (HTC calcined $>773 \mathrm{~K}$ ) or are plugged (SX Norit) by the accumulation of palmitic acid or reaction products on the pore surface. It can be speculated that the low functionalization with oxygenated groups gives rise to a more hydrophobic pore surface walls. Thus the non-polar tail of palmitic acid or methyl palmitic ester would stick strongly to the hydrophobic surface eventually leading to the occlusion of the micropores.

The catalysts prepared from HTC calcined at temperatures of $673 \mathrm{~K}$ or below exhibited only around $15-20 \%$ deactivation. The cause of deactivation is not the plugging of pores because the surface area determined by $\mathrm{CO}_{2}$ physisorption (Table 3) does not decreases significantly upon use. The higher functionalization of ultramicropores walls with oxygenated surface groups also would not favour the adsorption of the palmitic acid or palmitate on the pore walls, facilitating the circulation of reactant and product in the methanol solvent within the micropores. In some cases such as for $\mathrm{HTC}-673-\mathrm{SO}_{3} \mathrm{H}$, part 
of the deactivation could be attributed to some sulfonic acid groups leaching. However, catalyst prepared from HTC without heat treatment exhibited negligible sulfonic acid leaching and still the deactivation amounted to $15 \%$. As demonstrated previously [24], some important deactivation occurs by formation of the methyl sulfonyl ester when there are two acid groups in close proximity. Another possible cause of some deactivation is the morphological changes observed after reaction under stirring conditions. The sulfonated HTC carbon spheres initially have diameters of 300-400 nm (Figure 7 a-b). After two reaction runs, some spheres of larger diameters (about $2 \mu \mathrm{m}$ ) were formed (Figure 7d). The $\mathrm{HTC}-\mathrm{SO}_{3} \mathrm{H}$ submitted to a treatment with methanol under reflux for 72 hours without stirring did not suffer significant growth of HTC sphere diameter (Figure 7c). Therefore, the morphological changes can be due either to a mechanical effect of stirring or to the presence of palmitic acid. Further characterization should be performed to elucidate the reasons of the appearance of some huge spheres.

Peng et al. [22] found an optimum carbonization temperature for ordered mesoporous carbon of $873 \mathrm{~K}$ because higher temperatures decreased the sulfonic groups functionalisation. Kitano et al. [19] also found that the activity in esterification reaction decays when the temperature of pyrolisis of cellulose is above $773 \mathrm{~K}$ in agreement with our results for HTC carbon. They claimed that the higher activity is related to a higher density of sulfonic sites. This rational is no applicable to our case because the most active catalysts, i.e. HTC calcined at temperatures equal or below $773 \mathrm{~K}$, have similar sulfonic acid loading as that treated at $773 \mathrm{~K}$ and even lower loading than that treated at 973 K. Further characterization research is needed to ascertain unambiguously the reasons of the superior catalytic behaviour of sulfonated carbon catalyst prepared from HTC un-calcined or calcined at low temperatures. Future work should also address the testing of HTC calcined at low temperatures for a higher number of cycles. If the 
deactivation persist in successive runs, the major cause of deactivation for these catalysts, which seems to be the formation of surface methyl sulfonate esters [24], could be tackled, for instance, by spatially separating sulfonic acids on the surface of catalyst. The increase of some HTC sphere size upon successive runs for samples calcined at low temperatures $(<=673 \mathrm{~K})$ should be also studied in more detail.

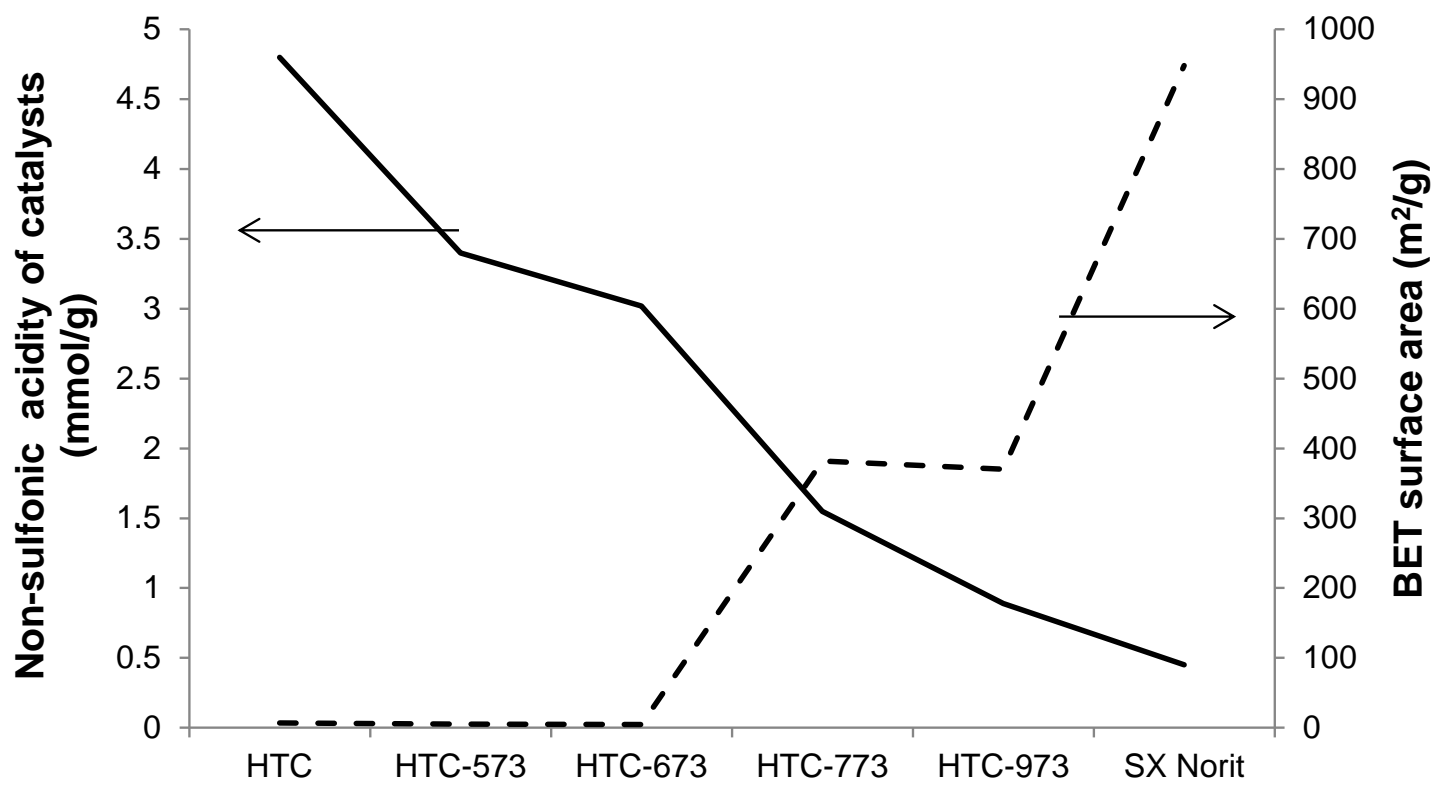

Carbon used as catalysts precursor

Figure 6. Non-sulfonic acidity of sulfonated catalysts (solid line, left y-axis) and BET surface area (dashed line, right y-axis) of the different carbon precursors used to prepare sulfonated catalysts. 

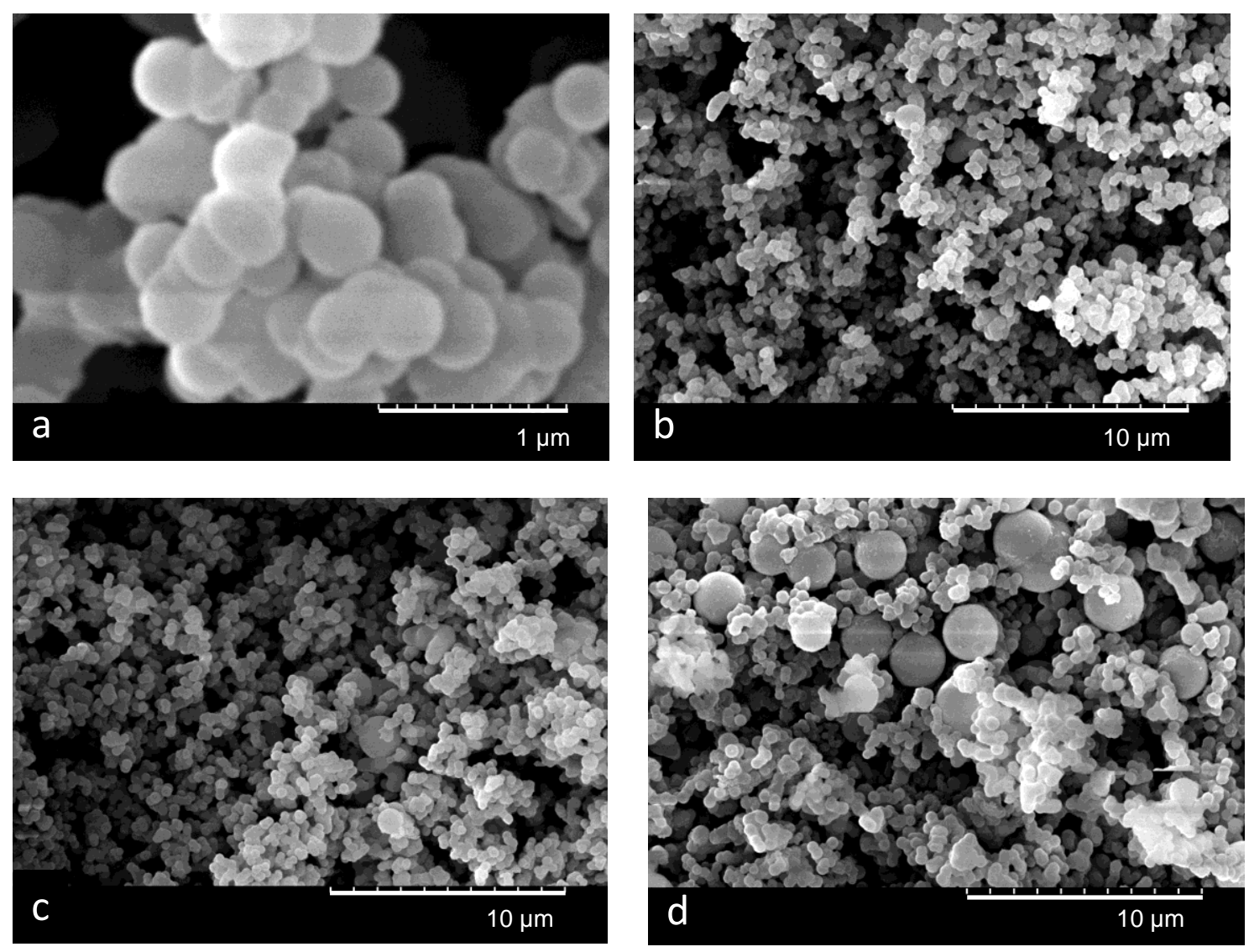

Figure 7. SEM images of (a,b) as-prepared $\mathrm{HTC}-\mathrm{SO}_{3} \mathrm{H}$ at two different magnifications and this catalyst after two different treatments: (c) treatment at methanol reflux without stirring during 72 hours, (d) after being used in esterification reaction for two consecutive runs under stirring.

\section{Conclusions}

Comparing the activity and deactivation performance of sulfonated catalyst prepared from HTC calcined at different temperatures, a turning point was observed for sulfonated catalyst prepared from HTC heat treated at around $773 \mathrm{~K}$. For lower heat treatment temperatures, the activity remains high and loss of activity upon reuse is only about $15-20 \%$. This deactivation is mainly due to formation of surface sulfonate esters 
although some morphological changes may also affect activity especially for catalyst prepared from un-pyrolyzed HTC. On the other hand, for catalysts pretreated at temperatures equal or above $773 \mathrm{~K}$, activity drops pronouncedly with respect to those prepared at lower temperatures and the activity after reuse decays more dramatically $(60-80 \%)$. In this later case, accumulation of reactants and products in the pores is the main cause of deactivation. The higher activity of catalysts prepared from HTC pyrolyzed at temperatures equal or below $673 \mathrm{~K}$ cannot be attributed to a higher surface loading of sulfonic groups. Thus the higher loading of non-sulfonic acid surface groups (carboxylic, phenolic) and, consequently, more hydrophilic surface may also contribute to the higher catalytic activity and less deactivation of catalyst prepared from HTC pyrolyzed at low temperatures. The finding that different deactivation processes prevail depending on surface functionalization and carbon structure could be transferred to other reactions involving organic molecules and to other carbon-based catalysts of different degree of graphitization.

\section{Acknowledgement}

This work was made possible by the financial support of the European Commission (FREECATS project, grant agreement No. 280658) and Spanish Ministerio de Economía y Competitividad (project CTQ2011-28124).

\section{References}

[1] S. Suganuma, K. Nakajima, M. Kitano, D. Yamaguchi, H. Kato, S. Hayashi, H. Michikazu, Journal of the American Chemical Society, 130 (2008) 12787.

[2] A. Demirbas, Energy Policy, 35 (2007) 4661.

[3] J. A. Melero, J. Iglesias, G. Morales, Green Chem., 11 (2009) 1285.

[4] G. Busca, Chem.Rev., 107 (2007) 5366. 
[5] A. Corma, Chem.Rev., 95 (1995) 559.

[6] B. L. Oliveira, V. Teixeira da Silva, Catal.Tod., 234 (2014) 257.

[7] Fine chemicals through Heterogeneous Catalysis R.A.Sheldon, H.van Bekkum (Eds.), Wiley-VCH;Weinheim, (2001) .

[8] J. Juan-Alcaniz, R. Gielisse, A. B. Lago, E. V. Ramos-Fernandez, P. SerraCrespo, T. Devic, N. Guillou, C. Serre, F. Kapteijn, J. Gascon, Catal.Sci.Technol., 3 (2013) 2311.

[9] A. P. Wight, M. E. Davis, Chem.Rev., 102 (2002) 3589.

[10] M. Hara, T. Yoshida, A. Takagaki, T. Takata, J. N. Kondo, S. Hayashi, K. Domen, Angew.Chem.-Int.Ed., 43 (2004) 2955.

[11] R. Luque, J. H. Clark, ChemCatChem, 3 (2011) 594.

[12] J. L. Figueiredo, J.Mater.Chem.A, 1 (2013) 9351.

[13] L. R. Radovic , F. Rodriguez-Reinoso , Chemistry and Physics of carbon, (Eds.), Dekker, New York, 1997, p.243

[14] R. Schlögl, Advances in Catalysis, C. Gates and Friederike Bruce (Eds.), Academic Press, 2013, p.103

[15] M. M. Titirici, M. Antonietti, Chem.Soc.Rev., 39 (2010) 103.

[16] A. Onda, T. Ochi, K. Yanagisawa, Top Catal, 52 (2009) 801.

[17] A. Takagaki, M. Toda, M. Okamura, J. N. Kondo, S. Hayashi, K. Domen, M. Hara, Catal.Tod., 116 (2006) 157.

[18] J. A. Macia-Agullo, M. Sevilla, M. A. Diez, A. B. Fuertes, Chemsuschem, 3 (2010) 1352.

[19] M. Kitano, K. Arai, A. Kodama, T. Kousaka, K. Nakajima, S. Hayashi, M. Hara, Catal.Lett., 131 (2009) 242.

[20] P. Lin, B. Li, J. Li, H. Wang, X. Bian, X. Wang, Catal.Lett., 141 (2011) 459.

[21] R. Liu, X. Wang, X. Zhao, P. Feng, Carbon, 46 (2008) 1664.

[22] L. Peng, A. Philippaerts, X. Ke, J. Van Noyen, F. De Clippel, G. Van Tendeloo, P. A. Jacobs, B. F. Sels, Catal.Tod., 150 (2010) 140.

[23] D. R. Stellwagen, F. van der Klis, D. S. van Es, K. P. de Jong, J. H. Bitter, Chemsuschem, 6 (2013) 1668.

[24] J. M. Fraile, E. García-Bordejé, L. Roldán, J.Catal., 289 (2012) 73.

[25] J. M. Fraile, E. García-Bordejé, E. Pires, L. Roldán, Carbon, 77 (2014) 1157. 
[26] L. Roldán, I. Santos, S. Armenise, J. M. Fraile, E. García-Bordejé, Carbon, 50 (2012) 1363.

[27] D. Lozano-Castelló, D. Cazorla-Amorós, A. Linares-Solano, Carbon, 42 (2004) 1233.

[28] F. Rodriguez-Reinoso, A. Linares-Solano, P.A.Thrower (Ed.), Chemistry and physics of carbon, Vol.21Marcel Dekker, New York, (1988) 1.

[29] IUPAC Recommendations, Pure Appl.Chem., 66 (1994) 1739. 